\title{
Research on Service Quality of "12306 China Railway" Mobile Ticketing Software
}

\author{
Yu Zhao ${ }^{1}$, Shize $\mathrm{Li}^{1 *}$, Yong Yang ${ }^{2}$ \\ ${ }^{1}$ Beijing Institute of Petrochemical Technology, Beijing 102617, China \\ ${ }^{2}$ Postdoctoral Programme, Bank of Zhengzhou, Zhengzhou 450018, China
}

Corresponding Author Email: 594779793@qq.com

https://doi.org/10.18280/rces.060202

Received: 2 February 2019

Accepted: 5 April 2019

\section{Keywords:}

mobile APP, 12306 China Railway, service quality, SERVQUAL scale

\begin{abstract}
In recent years, with the vigorous development of mobile application software market and the continuous growth of China railway, the official mobile application "12306 China Railway" has been increasingly used by the people to purchase train tickets. This paper aims to study the service quality of "12306" mobile ticketing software using the SERVQUAL scale. For this, the in-depth interview method combined with the service characteristics of mobile ticketing software to modify the original dimension and question of SERVQUAL scale, and then determine the adjusted SERVQUAL scale containing a total of 20 questions and 5 dimensions. Based on the revised SERVQUAL scale, the questionnaire survey was conducted to analyse the respondents' expected value and actual value of the "12306" mobile app through the data collection, and calculate the difference between perception and expectation of the users in the process of software ticketing. Finally, the problems with the service quality of 12306 mobile app was found through the reliability and validity analysis, and target suggestions were given.
\end{abstract}

\section{INTRODUCTION}

In recent years, mobile APP has been widely used in various information services due to its advantages of convenience, personalization, resource integration and rich user experience. The China Railway Customer Service Centre started the "12306 China Railway" online ticketing system in early 2012. So far, the 12306 mobile app has become the mobile ticketing software with the maximum customers and largest volumes. In general, 12306 is an app combining all the services a passenger needs from home to train station and train, and then off the train to the next destination. With a large user group and the most accurate source of ticket purchasing information, this app can greatly facilitate passengers' railway ticket purchase, but there also exist many problems in terms of service quality. The research on the service quality of 12306 mobile phone ticketing software can help to find out the problems in the quality of service and give related solutions, which shall improve the experience of ticker buyers when using this software, thus improving the quality of service for the entire mobile ticketing industry.

In this paper, the SERVQUAL scale was used for service quality evaluation, and its core is the customers' evaluation. The original SERVQUAL scale consists of five dimensions: tangibles, reliability, responsiveness, assurance, and empathy. Each dimension contains a variety of questions, totalling 22 items. In practical applications, the dimensions and question items of the SERVQUAL are corrected according to the problem studied to achieve the accuracy of service quality [1].

\section{LITERATURE REVIEW}

In the quantitative study of service quality, the appropriate research dimension can facilitate the research, and achieve the research purpose. Different scholars select different dimensions for studying the quality of mobile app services in different fields. Xuan [2] adopted three dimensions in the service quality study of the mobile library APP: functional quality, technical quality, and user care quality; a total of 34 question items were set in these three dimensions, and 12 items were set at most in functional quality dimension. Yang [3] set a total of nine dimensions in the service quality study of travel booking APP: confirmation degree, perceived usefulness, perceived quality, perceived trust, conversion cost, user habits, satisfaction, willingness to use, and continuous use behaviour, in which there were 28 questions. Xiao [4] set five dimensions for the research on the service quality of tourism mobile phone APP: performance perception, security, value perception, user satisfaction, and user loyalty; in the dimension of performance perception, six explanatory variables were set (effectiveness, system support, information integrity, communication achievement, convenience, and stability); a total of 22 questions were set in the questionnaire. Jiang [5] set up seven dimensions in the service quality research of mobile taxi app: quality, reliability, responsiveness, assurance, empathy, security, and system availability; in these seven dimensions, a total of 27 questions were set, of which reliability and responsiveness had 4 questions, respectively, and the responsiveness was the most weighted. Tian [6] designed seven dimensions in the customer loyalty study of online shopping APP: mobile phone, network speed, APP design, service quality, product quality, price concessions, APP security, with a total of 25 question items; in the dimension related to APP service quality, it's mentioned that the "search convenience" and "simple and convenient interface and easy operation" are the most weighted and relatively important. 


\section{STATUS ANALYSIS FOR THE SERVICE QUALITY OF "12306 CHINA RAILWAY" MOBILE TICKETING SOFTWARE}

\subsection{SERVQUAL scale correction}

In this paper, the in-depth interviews were conducted for 20 respondents at five age levels $(20,20-30,30-40,40-50$, and above 50 years old), 2 males and 2 females at each level. During the in-depth interviews, firstly the service quality of 12306 mobile APP and the principle of the SERVQUAL scale were introduced to the respondents. Then they were inquired about whether each dimension of the SERVQUAL original scale is important for this app. Afterwards, they were asked about whether each question in the SERVQUAL scale is important. Finally, the respondents put forward some other questions and dimensions (not included in the SERVQUAL original scale) capable of evaluating the 12306 mobile app according to the characteristics of the APP. Thus, through correcting the dimensions and questions based on the results of the in-depth interview, the dimensions and questions of the final SERVQUAL scale were formulated.

Through in-depth interviews with respondents, it's seen that "responsiveness", "reliability" and "assurance" were more important for the respondents, with the frequency of more than $50 \%$, so these three dimensions were retained in the revised scale, but deleting the two dimensions of the "empathy" and "tangibles" with the frequencies below $50 \%$. Among the 20 respondents, more than half required to have new dimensions of "convenience" and "availability". Therefore, these two dimensions were added in the revised scale.

Based on the results of in-depth interviews, the original SERVQUAL scale was adjusted properly according to the function and service mode of the 12306 mobile APP as well as the respondents' responses, by deleting the questions that were deemed to be unimportant by the respondents with the frequency less than $50 \%$, and retaining and adding questions with a frequency of more than $50 \%$. Finally, in this paper, the "tangibles" and "empathy" were removed from the SERVQUAL scale, and "availability" and "convenience" were added. Further, in the added dimension of availability, new questions were added, i.e., "app operation is simple", "app runs stable" ,"in the app, all kinds of service information can be easily found", and "app server is stable"; in the dimension of convenience, it added "online ticketing is simple and fast", "login interface is convenient and simple", "train seats and berths can be easily selected". Besides, the dimensions in the original scale such as the "reliability", "responsiveness", "assurance" were retained, and the questions were adjusted accordingly. Thus, the revised SERVQUAL scale suitable for the 12306 mobile ticketing software was ultimately obtained, as shown in Table 1.

Table 1. Revised SERVQUAL scale

\begin{tabular}{|c|c|}
\hline Dimension & Questions \\
\hline Availability & $\begin{array}{c}\text { App operation is simple } \\
\text { App runs stable } \\
\text { All kinds of service information are easily found } \\
\text { App server is stable }\end{array}$ \\
\hline Reliability & $\begin{array}{l}\text { Various services are completed in time } \\
\text { Reliable catering, car-booking, and credit services are available on } 12306 \text { app } \\
\text { Correct train number and seat information is provided } \\
\text { The service in line with } 12306 \text { mobile app is provided }\end{array}$ \\
\hline Responsiveness & $\begin{array}{l}\text { Passengers are provided with ticketing service in a timely manner } \\
\text { Passengers are provided with catering, car and other follow-up services in time } \\
\text { Passengers are provided with information on the train number in time }\end{array}$ \\
\hline Assurance & $\begin{array}{c}\text { It's assured that passengers can purchase tickets successfully } \\
\text { It's assured that passengers can change trains within the specified time } \\
\text { It's assured about reasonable fare } \\
\text { Reasonable prices are provided for all types of services } \\
\text { Passengers feel relieved when using services other than booking } \\
\text { The problems encountered by passengers are solved when using the app } \\
\end{array}$ \\
\hline Convenience & $\begin{array}{c}\text { Online ticketing steps are simple and fast } \\
\text { Login interface is convenient and concise } \\
\text { Seats and berths in the train are easily selected }\end{array}$ \\
\hline
\end{tabular}

\subsection{Analysis for survey process and basic questionnaire information}

In this study, the scale was converted into the questionnaire for pre-survey, which can help to adjust the language content of the questionnaire, and facilitate the understanding and completion of the respondents. The seven-point Likert scale method was adopted. So, in the design of questionnaires, the evaluation "very poor" to "very good" correspond to 1-7 points respectively, and then the respondents can make selection according to their expectations and actual perceptions of each question.

The survey was conducted in two methods: online survey and field survey. The online questionnaires were collected by the online platform WJX, and finally 216 questionnaires were received; after eliminating the invalid questionnaires, a total of 207 valid questionnaires were obtained. In the field survey, a total of 157 questionnaires were collected, of which 23 questionnaires were invalid questionnaires, and 124 were valid questionnaires. In the end, there were 331 online and offline valid questionnaires. In addition, the number of respondents aged 21-30 was the largest, up to 163, which is the main force to use 12306 mobile app; 69 respondents were aged 31-40, in a second place. Table 2 lists the related detailed information. In this paper, the 331 valid questionnaires were taken as the data source for studying the service quality of the 12306 mobile ticketing software using the SERVQUAL scale, and then the analysis of the questionnaire subjects was conducted. 
Table 2. Age distribution of SERVQUAL scale

\begin{tabular}{c|c|c|c}
\hline Age distribution & Frequency/person & Percentage $(\%)$ & Cumulative percentage (\%) \\
\hline Below 20 & 13 & 3.9 & 3.9 \\
$21-30$ & 163 & 49.2 & 53.1 \\
$31-40$ & 69 & 20.8 & 73.9 \\
$41-50$ & 55 & 16.6 & 90.6 \\
Above 50 & 31 & 9.4 & 100 \\
\hline Total & 331 & 100 & \\
\hline
\end{tabular}

\subsection{Analysis for service quality scores}

According to the formula $\mathrm{SQ}=\sum_{i=1}^{n} P i-E i\left(\mathrm{P}_{\mathrm{i}}\right.$ represents the customer perceived score, and $\mathrm{E}_{\mathrm{i}}$ represents the customer expected score; $i=1,2,3, \ldots, n$ ), the service quality scores of the 12306 mobile app were calculated. At SQ>0, the perceived score of service quality exceeds the customer's expected score, indicating that the customer is very satisfied with the service quality; at $\mathrm{SQ}=0$, the perceived service quality is equal to the customer's expectation, indicating the customer is basically satisfied with the service quality; at $\mathrm{SQ}<0$, perceived service quality is lower than customer expectations, indicating poor service quality for the customers.

The results of this study were: SQ score was -16.17 , and the average score of 20 question points was -0.81 , indicating that the overall perceived service quality of 12306 mobile fails to meet the customer's expectations, and none of the 20 questions can meet the customer's expectations in terms of perceived service quality.

\subsection{Reliability and validity analysis for the service quality of 12306 China railway mobile ticketing software}

For the reliability analysis, using the spss 23 software, it's calculated that the Cronbach's Alpha coefficient of the perceptual part of the data collected in this paper was 0.836 , and that of the expected part was 0.845 , both exceeding 0.8 . This indicates a greater internal consistency of data, higher reliability, and smaller measurement error. Table 3 shows the Cronbach's Alpha coefficients for each dimension in the SERVQUAL scale.

Table 3. Cronbach's Alpha coefficients in each dimension

\begin{tabular}{c|c|c}
\hline Dimension & Cronbach's Alpha(perception) & Cronbach's Alpha(expectation) \\
\hline Availability & 0.803 & 0.821 \\
\hline Reliability & 0.812 & 0.828 \\
\hline Responsiveness & 0.811 & 0.822 \\
\hline Assurance & 0.887 & 0.902 \\
\hline Convenience & 0.869 & 0.856 \\
\hline
\end{tabular}

As above, the Cronbach's Alpha coefficients of the five dimensions was basically higher than 0.8 , indicating a higher internal consistency and reliability of the data. Then the spss 23 software was used to conduct the correlation analysis of the 20 questions in this paper, finding that the total correlation coefficient of each dimension was greater than 0.5 , so, these questions meet the requirements, and the structural rationality of the service quality measurement was also verified.

Validity analysis is mainly used for the rationality and significance of the research. The factor analysis, one method of validity analysis, was then adopted to make comprehensive analysis using different indicators such as KMO value, Bartlett spherical test, variance interpretation rate, and factor load coefficient, and then verify the validity level of the data. The $\mathrm{KMO}$ value was used to determine the validity, the Bartlett spherical test was for detecting the independence between the variables. Table 4 lists the KMO value and the Bartlett sphericity test of the survey data.

It can be seen from Table 4 above that the KMO value was 0.949 (greater than 0.6), the Bartlett sphericity test value was 2837.89 , and the corresponding significance value was 0 (less than 0.01). The survey data conforms to the normal distribution, there is high independence between the variables, and the question has research significance.

Table 4. KMO value and Bartlett sphericity test of survey data

\begin{tabular}{c|c|c}
\hline \multicolumn{2}{|c|}{ KMO } & 0.949 \\
\hline Bartlett sphericity test & Chi-square distribution & 2837.89 \\
\hline & Degree of freedom & 190 \\
\hline & Significance & 0 \\
\hline
\end{tabular}

\section{EXISTING PROBLEMS IN THE SERVICE QUALITY OF THE 12306 MOBILE TICKETING SOFTWARE}

According to the difference of the above questions, we analysed the problems with service quality of 12306 mobile app. The related problems were summarized from the five dimensions below.

\subsection{Availability dimension}

The SQ score in the availability dimension was -4.06 , indicating that there is a large quality of service problem. In this dimension, the scores of the questions "APP operation is 
simple" and "APP runs stable" were relatively low, which indicates that the 12306 mobile app is relatively low in operation; in the age group applicable to the software, the majority of people were aged 21-40 who can operate the mobile phone better, but the question " APP operation is simple " still scored very low, indicating that the 12306 mobile app is not complete and stable enough, and it is prone to errors.

\subsection{Reliability dimension}

The score in the reliability dimension was -2.95 . In this dimension, the score of the question " reliable catering, booking and credit card services are provided on 12306 mobile app" was relatively higher than other questions, indicating that there is low difference between the perception and expectation values of the passengers when they are faced with this question. This service is not the main business of this app, and plays a minor role in improving the overall service quality perception of customers. In addition, there is also the problem with the app that various service information provided is inconsistent with the described in the 12306-mobile app.

\subsection{Responsiveness dimension}

The score in the responsiveness dimension was -2.33. In this dimension, "passengers are provided with ticketing services in a timely manner" and "passengers are provided with catering, car and other follow-up services in a timely manner" were low in scores, while the question "passengers are provided with information on their train number in time" scored relatively higher for the customers. This indicates that passengers are not able to enjoy ticketing services and follow-up services such as catering and car-related services when using 12306 mobile app. Although this app can provide information on the train number, it's not good enough to ensure the timely purchase of tickets, and fails to meet the meet passenger expectations in terms of catering and car-booking service.

\subsection{Assurance dimension}

The score in the assurance dimension was -4.77 . The "fair fare" score indicates that the user's perception of the fare differed less from the expectation, but this cannot be controlled by software. The "Reasonable prices are provided for various types of services " had the lowest score, which indicates that users are less satisfied with the use of this app other than the ticketing service. Besides, the two scores of "it's assured that passengers can purchase tickets successfully" and "it's assured that passengers change trains within a specified time" were also relatively low, indicating that passengers' expectations for ticket purchases and exchanges differ greatly from the perception in the assurance dimension.

\subsection{Convenience dimension}

The score in the convenience dimension was -2.36 , which is relatively low in the service quality. In this dimension, the "online ticketing is simple and fast" scored the lowest, indicating that the online ticket purchase step is more cumbersome for the users, with a large difference from the actual expectation. Then, "the train seat and berth can be easily selected" also scored low, indicating that the user perceives poor service quality when selecting the seats or berths on the app, and fails to obtain a better user experience.

\section{COUNTERMEASURES FOR IMPROVING THE SERVICE QUALITY OF 12306 MOBILE TICKETING SOFTWARE}

\subsection{Promoting the software quality}

In the dimensions of "availability" and "convenience", the user was not satisfied with the operation of 12306 mobile app. As the official railway mobile ticketing software of China Railway, its purpose is to provide high quality ticketing service for the public, so the process of ticket purchase should be simplified, and its function should be maximized, so as to ensure the more clear interface, reasonable design, more logical operation, and passengers can easily find the function that they require during the use [7]. Therefore, 12306 mobile app should first improve the interface design and operation logic of its app so that it can better meet the needs of passengers. Secondly, it should optimize the network, especially the network blocking problem that occurs when purchasing tickets. In addition, considering its large mobile users, the official should increase investment in servers [8].

\subsection{Improving ticketing service}

The ticketing service is the main business of 12306 mobile app. The user uses this app mainly for purchasing train tickets by the mobile phone. Therefore, the ticket purchase service is also the top priority for improving the service quality. Based on the overall SERVQUAL scale scores and the actual situation, the study found that in the normal working days, it is easy to buy tickets, but in the holiday or student holiday, tickets in many places are not easy to buy. Excluding the factors of the existing train schedule, there are problems in the releasing and purchasing process of tickets [9]. First of all, 12306 mobile app should adopt a method of time-phased network ticketing. Nowadays, the ticketing time is relatively concentrated, causing some users to be unable to purchase the tickets due to the constraint of time and equipment. In addition, this app needs to optimize the network server. When the user purchases the ticket, it should be ensured that the user can purchase the ticket smoothly using the ticketing app, and the server cannot be collapsed due to the excessive number of users. Finally, a more reasonable ticketing experience should be designed. The redundant steps in purchasing tickets may result in many older users not being able to obtain the tickets in a short period of time, so the way to purchase tickets should be simplified or necessary information is filled in earlier for improving the efficiency of ticket purchase [10].

\subsection{Providing more reliable additional services}

As the official mobile software of China Railways, 12306 mobile app should provide more reliable and complete additional services. According to the survey results obtained in the "reliability" and "response" dimensions, there exist some problems with service quality in the extra services. First of all, 12306 mobile app should provide passengers with reliable railway catering, car and other additional services. The latest version of this app provides services such as catering, tourism services, and specialty products, but only catering is officially provided, and the rest are all similar to advertising services. They provide services only by telephone or purchase of website, instead of the official service by 12306 app", so many customers are not satisfied. 12306 mobile app should be 
closely linked to the car, catering and specialty services, so that all services can be enjoyed in one stop through the mobile app, which will enable passengers to be more assured when using these additional services, and will also enhance the service quality of this app as a whole [11]. In addition, it also ensures that the additional services provided are guaranteed and should be reasonably priced, so that users can feel the same assured service in all the services of 12306 mobile app, and excessive service cannot be over-charged on some pricesensitive services such as food ordering and speciality products etc.

\subsection{Adding user alert service}

In 12306 mobile app, users sometimes cannot get timely information reminders on how long before it starts to sell a ticket for a certain train, how long before one can change the train number, and how long before the train is about to leave. Sometimes, because of the non-striking font on the ticket, the user might misread the station name, e.g., the user misread Beijing South station as Beijing West station, so he shall miss the train [12]. Therefore, in this app, the eye-catching reminder should be appropriately added. When the passengers purchase the ticket, they should be reminded of the boarding time, the boarding location, and the modified information of the train number in the mobile app one day earlier, so as to avoid missing the train because of ticket information misreading [13$14]$.

\section{CONCLUSIONS AND LIMITATIONS}

In this process of survey research, the sample has certain limitations. First, the respondents were from mainly the Beijing area, so they can only represent the respondents in Beijing area about the service quality of the 12306 mobile ticketing software. The conclusions of this study may have different results when applied in the whole country or other regions. Therefore, if the service quality of the 12306 mobile app needs to be further improved in the future, the geographical location of the respondent should be taken into account. In addition, this paper only used the SERVQUAL scale method in service quality research. Although the SERVQUAL scale is already a mature method of service quality assessment, it lacked statistical analysis data such as factor analysis, and did not add weights on the questions for each dimension, which may draw the conclusions with certain limitations. In the future, the content of factor analysis and weights to the questions in each dimension should be added, so as to continuously refine the content and then obtain more accurate and comprehensive results of service quality research.

\section{ACKNOWLEDGMENT}

This study was funded by the Key projects of the National Natural Science Foundation of China (Item Number: 71832015) and the Scientific Research Training Project of University Students of Beijing institute of petrochemical technology.

\section{REFERENCES}

[1] Tang, Y.Y., Li, W.W. (2016). Customer satisfaction evaluation of railway freight service quality based on SERVQUAL. Chinese Railways, (8): 15-19. http://dx.chinadoi.cn/10.3969/j.issn.1001683X.2016.08.004

[2] Xuan, S.X. (2015). Research on app service quality evaluation of mobile library based on user perception. Nanjing Agricultural University.

[3] Yang, C.X. (2018). Research on sustainable use behavior of app users in tourism reservation class. Ji'nan University.

[4] Xiao, Y.K. (2016). An empirical study on the influencing factors of app user satisfaction in tourist mobile phone. Central China Teachers' University.

[5] Jiang, T.F. (2018). Research on service quality evaluation of mobile taxi app based on SERVQUAL model. Liaoning University.

[6] Tian, X. (2017). Countermeasures to improve customer M-loyalty of mobile app online-shopping. Journal of Dezhou University, 33(6): 42-46, 84.

[7] Liu, X.Y., Huang, X.P. (2016). Research on user's continuous use willingness of mobile magazine app. Journalism Research Herald, 7(24): 41. http://dx.chinadoi.cn/10.3969/j.issn.16748883.2016.24.026

[8] Li, J.C. (2018). 12306 revamp, experience of railway ticket purchase website. Computer and Network, 44(22): 40 .

[9] Cao, Y. (2017). Research on service quality of railway ticket order based on 12306 website and mobile client. Technology and Market, 24(4): 227-228. http://dx.chinadoi.cn/10.3969/j.issn.10068554.2017.04.122

[10] Duan, H.Q. (2017). Research and Discussion on online booking system. Fujian Computer, 33(3): 149-150. http://dx.chinadoi.cn/10.16707/j.cnki.fjpc.2017.03.080

[11] Liu, Z.H., Li, J.B., Wang, L.H., Yan, Z.Y. (2016). Passenger service of 12306 website. Railway Computer Application, 25(10): 38-40. http://dx.chinadoi.cn/10.3969/j.issn.10058451.2016.10.009

[12] Pan, Y., Lv, X.Y., Dai, L.L., Zhu, Y.T. (2014). Research on phenomena of maliciously cancelling orders for railway Internet users. Railway Computer Application, 23(04): 5-8. http://dx.chinadoi.cn/10.3969/j.issn.10058451.2014.04.002

[13] Guo, P.Q., Zhang, J. (2016). Analysis of the problem of ticket purchase for migrant workers under the background of "Internet +" -- Taking "railway 12306" mobile phone ticketing client as an example. Rural Economy and Science-Technology, 27(19): 261-263. http://dx.chinadoi.cn/10.3969/j.issn.10077103.2016.19.109

[14] Treen, E., Pitt, L., Bredican, J., Farshid, M. (2016). App Service: How do consumers perceive the quality of financial Service Apps on smart devices? Journal of Financial Services Marketing, 22(3): 119-125. https://doi.org/10.1057/s41264-017-0029-2 